\title{
Close association of HLA-B51 and B52 in Israeli patients with Behçet's syndrome
}

\author{
N Arber, $\mathbf{T}$ Klein, $\mathbf{Z}$ Meiner, E Pras, A Weinberger
}

Department of Medicine ' $D$ ', Beilinson Medical Center, and the Sackler Faculty of Medicine, Tel Aviv University, Ramat Aviv, Israel N Arber E Pras

Tissue Typing Laboratory, Beilinson Medical Center, and the Sackler Faculty of Medicine, Tel Aviv University, Ramat Aviv, Israel

$T$ Klein

Department of Neurology, Hadassah School of Medicine, Hebrew University, Jerusalem, Israel $\mathrm{Z}$ Meiner

Department of Medicine ' $B$ ' and the Rheumatology Unit, Beilinson Medical Center, and the Sackler Faculty of Medicine, Tel Aviv University, Ramat Aviv, Israel A Weinberger

Correspondence to:

Professor A Weinberger, Department of Medicine ' $\mathrm{B}$ ', Beilinson Medical Center, 49100 Petah Tiqva, Israel. Accepted for publication 16 May 1990

\begin{abstract}
Epidemiological data, family history, clinical data, and HLA typing were studied in three groups of patients with Behçet's syndrome: six Israeli Ashkenazi Jews, 29 non-Ashkenazi Jews, and three Israeli Arabs. HLA-B51 and B52 were present in $24 / 38(63 \%)$ and $8 / 38$ (21\%), respectively, of the patients compared with 13/151 (9\%) of the control group for both cases, a relative risk of 18.2 and 2.8 respectively. The syndrome was found in six of the 34 families. Ninety five per cent of the affected family members were either B51 or B52 positive. Eleven of the 14 families (79\%) chosen for study contained a close relative of the proband who had recurrent oral ulcers. All the relatives with ulcers, except for one, were B51 or B52 carriers. Recurrent oral ulcers in the patients with Behçet's syndrome began a few years before other manifestations of the syndrome occurred.
\end{abstract}

Our findings suggest that (a) HLA-B51 and HLA-B52 are primarily associated with Behçet's disease of Israeli patients; (b) the familial occurrence of this syndrome is high and occurs predominantly in the B5 positive group; (c) recurrent oral ulcers may be the first symptom of Behçet's syndrome, appearing early in life; HLA analysis can provide the chue for a correct diagnosis; (d) ulcer recurrence is common among members of a family containing a patient with Behçet's syndrome.

Behçet's syndrome is a multisystem disease that may affect the mucocutaneous, occular, intestinal, articular, vascular, pulmonary, and neurological systems. Aphthous oral ulcers are usually the first manifestation occurring in nearly all patients. These ulcers develop on the mucous membranes of the lip, gingiva, cheeks, and also on the scrotum and the vulva.

The disease is especially common in Japan, where its prevalence has been estimated at one in 10000 population, ${ }^{1}$ and in the Middle East.

Previous studies have shown that a certain immunogenetic predisposition is present in the development of Behçet's syndrome, which is closely associated with HLA-B51. The prevalence of HLA-B51 was shown to be substantially increased in patients, whereas HLA-B52 showed no substantial difference in patients and controls. $^{2}$

Familial involvement has been repeatedly but infrequently reported. ${ }^{3}$ There seems to be little information on the prevalence of the disease, or some of its features, in relatives of those with Behçet's syndrome.

Israel has a population that originated from many countries: Ashkenazi Jews from Europe, and non-Ashkenazi Jews and Arabs of Mediterranean and Middle Eastern origin. The purpose of this study was, therefore, to investigate the prevalence of HLA-A, B, and C antigens in Israeli patients with Behçet's syndrome and to analyse the epidemiology, clinical picture, and family history of those subjects in whom HLAB51 or B52 was present.

\section{Patients and methods}

Thirty eight patients with Behçet's syndrome were selected from the rheumatology outpatient clinic at the Beilinson Medical Center, Petah Tiqva, Israel. The diagnosis of Behçet's syndrome was based on the criteria of the Behçet's Disease Research Committee of Japan. ${ }^{4}$

HLA typing was performed on those family members of patients with Behçet's syndrome who had oral ulcers.

Peripheral blood lymphocytes were separated on a Ficoll-Hypaque density gradient. HLA-A and $B$ tissue typing was performed by the standard two stage National Institute of Health microlymphocytotoxicity technique.

Comparisons of the prevalence of antigens in the patient and control groups was done using a $2 \times 2$ table with the $\chi^{2}$ test.

\section{Results}

HLA-B51 was found in $24 / 38(63 \%)$ of the patients compared with $13 / 151$ (9\%) of controls; relative risk $=18 \cdot 2, \mathrm{p}<0.0001$. HLA-B52 was disproportionately represented among Israeli patients with Behçet's syndrome, being found in $8 / 38(21 \%)$ compared with $13 / 151(9 \%)$ of controls; relative risk $=2.8, \mathrm{p}<0.05$ (table 1). Clinically, no significant difference was noted between the patients with the B51 and the B52 antigens, both groups having the same manifestations with the same degree of severity. Of the Behçet's syndrome family members who had oral ulcers only, $94 \%$ were HLA-B51 or B52 positive (table 2). No significant difference was found between Ashkenazi Jews, nonAshkenazi Jews, and Arabs in clinical manifestation or HLA typing except for the occular disease, which was uncommon in the Ashkenazi Jews (table 3).

The figure illustrates a family tree of those with Behçet's syndrome and recurrent oral ulcers. 
Table 1 Number (\%) of patients with HLA-A and $H L A-B$ antigens in Behçet's disease

\begin{tabular}{|c|c|c|}
\hline$H L A$ antigen & $\begin{array}{l}\text { Controls subjects (\%) } \\
(n=151 \text { Israeli) })^{9}\end{array}$ & $\begin{array}{l}\text { Patients (\%) } \\
(n=38)\end{array}$ \\
\hline $\begin{array}{l}\text { A1 } \\
\text { A2 } \\
\text { A3 } \\
\text { A11 } \\
\text { A25 } \\
\text { A26 } \\
\text { A28 } \\
\text { A29 } \\
\text { Aw23 } \\
\text { Aw24 } \\
\text { Aw30 } \\
\text { Aw31 } \\
\text { Aw32 } \\
\text { Aw33 } \\
\text { Aw34 } \\
\text { B5 } \\
\text { B7 } \\
\text { B8 } \\
\text { B13 } \\
\text { B14 } \\
\text { B15 } \\
\text { B17 } \\
\text { B18 } \\
\text { B27 } \\
\text { B37 } \\
\text { B40 } \\
\text { Bw21 } \\
\text { Bw22 } \\
\text { Bw35 } \\
\text { Bw38 } \\
\text { Bw39 } \\
\text { Bw41 } \\
\text { Bw44 } \\
\text { Bw45 } \\
\text { Bw49 } \\
\text { Bw50 } \\
\text { Bw51 } \\
\text { Bw52 } \\
\text { Bw56 }\end{array}$ & $\begin{array}{r}38(25) \\
39(26) \\
29(19) \\
26(17) \\
1(1) \\
28(19) \\
24(16) \\
15(10) \\
3 \quad(2) \\
25(17) \\
14(9) \\
3(2) \\
6(4) \\
11(7) \\
5(3) \\
2(1) \\
14(9) \\
10(7) \\
7(5) \\
29(19) \\
6(4) \\
14(9) \\
9(6) \\
6(4) \\
2(1) \\
8(5) \\
1(1) \\
6(4) \\
50(33) \\
31(21) \\
1(1) \\
13(9) \\
21(14) \\
1(1) \\
6(4) \\
5(3) \\
13(9) \\
13(9)\end{array}$ & 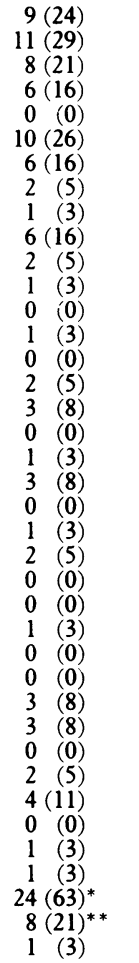 \\
\hline
\end{tabular}

${ }^{*} \mathrm{p}<0.0001 ;{ }^{* *} \mathrm{p}<0.05$.

Table 2 Family members with oral ulcers only

\begin{tabular}{llll}
\hline $\begin{array}{l}\text { Patient's } \\
\text { HLA }\end{array}$ & Relative & $\begin{array}{l}\text { Selected } \\
\text { relatives } \\
\text { HLA }\end{array}$ & Origin \\
\hline B51 & Son & B51 & Non-Ashkenazi \\
& Son & B51 & Non-Ashkenazi \\
& Daughter & B51 & Non-Ashkenazi \\
& Daughter & B51 & Non-Ashkenazi \\
B52 & Grandson & B51 & Non-Ashkenazi \\
& Son & B52 & Non-Ashkenazi \\
B51 & Son & B52 & Non-Ashkenazi \\
B5 & Uncle & B51 & Ashkenazi \\
B51;52 & Daughter & B5 & Ashkenazi \\
B51 & Daughter & B52 & Non-Ashkenazi \\
B51 & Father & B51 & Non-Ashkenazi \\
B51 & Son & B51 & Non-Ashkenazi \\
& Daughter & B51 & Non-Ashkenazi \\
& Daughter & B51 & Non-Ashkenazi \\
& Daughter & B51 & Non-Ashkenazi \\
& Son & B51 & Non-Ashkenazi \\
& Son & B51 & Non-Ashkenazi \\
B35 & Daughter & B35 & Non-Ashkenazi \\
\hline
\end{tabular}

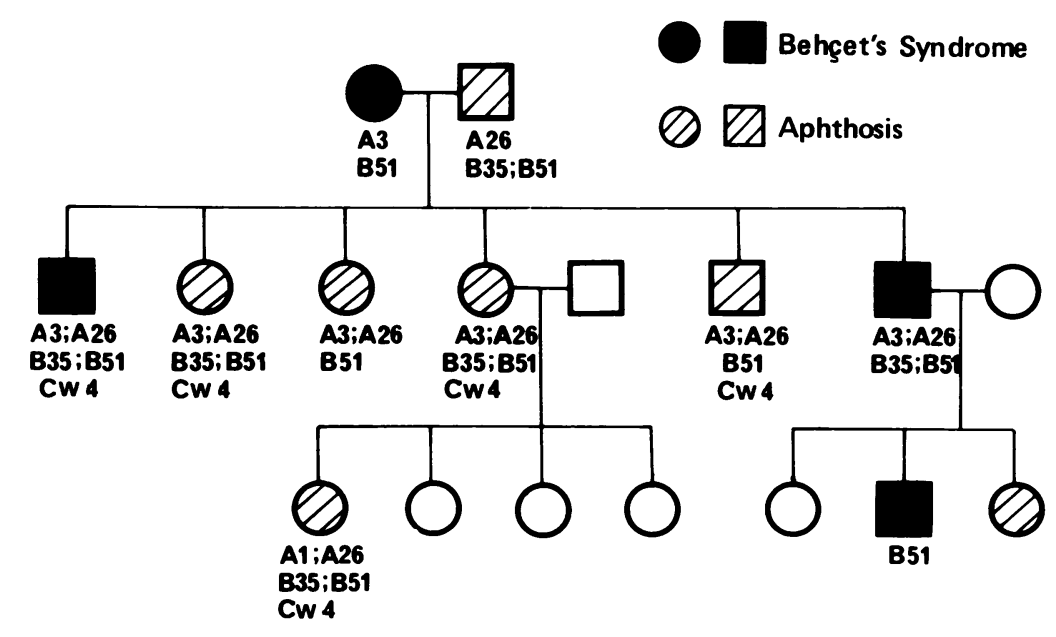

HLA haplotypes in a family with Behçet's syndrome and oral ulcers.
Table 3 Clinical manifestations in 38 patients with Behçet's syndrome. Results are given as number (\%) of patients

\begin{tabular}{|c|c|c|c|}
\hline & $\begin{array}{l}\text { Ashkenazi } \\
(n=6)\end{array}$ & $\begin{array}{l}\text { Non-Ashkenazi } \\
(n=29)\end{array}$ & $\begin{array}{l}\text { Arab } \\
(n=3)\end{array}$ \\
\hline Oral ulcers & $6(100)$ & $29(100)$ & $3(100)$ \\
\hline Arthritis & $6(100)$ & $29(100)$ & $3(100)$ \\
\hline Genital ulcers & $4 \quad 67)$ & $18 \quad 62)$ & $2(67)$ \\
\hline Skin lesions & $2(33)$ & 8 & $1 \quad 33)$ \\
\hline Vascular disease & $2(33)$ & $6 \quad(21)$ & 1 (33) \\
\hline $\mathrm{CNS}^{*}$ disease & $2(33)$ & 11 & $2(67)$ \\
\hline Occular disease & 0 & $8(28)$ & 1 (33) \\
\hline
\end{tabular}

"CNS = central nervous system.

\section{Discussion}

Classical Behçet's syndrome is fairly easy to recognise because of the triad of features: mouth ulceration, genital ulceration, and iritis, but less complete cases are more difficult to distinguish. We believe, therefore, that the prevalence of 1 in 10000 is even higher among the Israeli population. A screening for incomplete Behçet's syndrome among the Israeli population is now in process.

Relatives of patients with Behçet's syndrome have high incidence of recurrent oral ulcers only. The ulcers are of the same type as those in the patients but rarely of the same severity. HLA typing of those subjects with recurrent oral ulcers showed that $94 \%$ had B51 or B52. It is suggested, therefore, that the two antigens play a significant part in the genetic predisposition towards mouth ulcers. The question remains, however, whether or not those subjects with recurrent oral ulcers will develop full blown Behçet's syndrome during their lifetime.

Investigations of HLA-A and B antigens in recurrent aphthous stomatitis have shown an association with $\mathrm{B} 12$, whereas the prevalence of the B5 antigen was decreased significantly. ${ }^{56}$ These observations raise the possibility that recurrent aphthous stomatitis and Behçet's syndrome are not the same disease; recurrent oral ulcers are associated with a high prevalence of B51 or B52 and one or more other family member has Behçet's syndrome. The current data indicate that when B51 or B52 are present in a subject with recurrent oral ulcers a careful screening for Behçet's syndrome in the family should be made.

The familial occurrence of Behçet's syndrome has rarely been reported in the past. Recently, Chajek-Shaul et al reported that in $10 \%$ of Israeli families other relatives were also affected. ${ }^{7}$ In our study familial occurrence of the syndrome was described in six of 34 families. Ninety five per cent of affected family members were B51 or B52 positive. Thus, probably, inheritance plays an important part in providing a stimulant for the development of Behçet's syndrome.

Our study indicates that Behçet's syndrome is closely associated with HLA-B51 or B52, which are split antigens of HLA-B5. Relative risk for B51 was $18.2(p<0.0001)$ and for B52 $2 \cdot 8$ $(\mathrm{p}<0.05)$. Subjects with HLA-B51 or B52 are considered at greater risk of developing Behçet's syndrome. Our data differ from those of others who found no association between Behçet's syndrome and HLA-B52. ${ }^{2}$ 
Indeed, a recent study from Jerusalem indicated that the gene prevalence of B51 among patients with Behçet's syndrome was 0.708 with a relative risk of $17 \cdot 1$, while $\mathrm{B} 52$ was not associated with the disease. ${ }^{7}$ The difference between our study and the Jerusalem one may be attributed to the difference between the patients of both centres. Our rheumatology clinic treats many non-Ashkenazi Jews, among them many Iraqi Jews but very few Arabs. The antigen prevalence of $\mathrm{B} 51$ and $\mathrm{B} 52$ in nonAshkenazi Jews is 0.108 and 0.133 with gene prevalence of 0.56 and 0.69 respectively. In Ashkenazi Jews the antigen prevalence of B51 and B52 is 0.040 and 0.098 and the gene prevalence 0.02 and 0.50 respectively (Brautbar $\mathrm{C}$, personal communication). The Babylonians (Iraqi Jews) are unique among Jewish ethnic groups because of their particular history, which is restricted to the Middle East, and their extremely high inbreeding rate. ${ }^{8}$ The prevalence of various alleles is like that of Asiatics and Middle Easterners-namely, a high prevalence of B5 and relatively lower prevalences of B7, $\mathrm{B} 8$, and B12. Whereas the prevalence of HLAB5 is 0.145 in this particular ethnic group, ${ }^{8}$ the prevalence of its split antigens is not yet known (Brautner C, personal communication).

The current data indicate that the presence of
HLA-B51 and B52 in a selected patient population may serve as an additional clue for the diagnosis of Behçet's syndrome in symptomatic patients. The presence of one of these antigens in a subject with recurrent oral ulcers raises the possibility that he is a member of a family in which at least one other person has Behçet's syndrome.

1 Maeda K, Agata T, Nakae K. Recent trends of Behcet's disease in Japan and some of its epidemiological features. disease in Japan and some of its epidemiological features. In: Inaba G, ed. Behfet's

2 Ohno S, Ohguchi M, Hirose S, Matsuda H, Wakisaka A, Aizawa M. Close association of HLA-Bw51 with Behçet's disease. Arch Ophthalmol 1982; 100: 1455-8.

3 Chamberlain M A. A family study of Behçet's syndrome. Ann Rheum Dis 1978; 37: 459-65.

4 Momoi H, Inaba G, Mimura Y. Guidance for diagnosis of Behçet's disease. In: Inaba G, ed. Behcet's disease. Tokyo: University of Tokyo Press, 1982: 1-10

5 Challacombe J J, Batchelor J R, Kennedy L A, Lehner T. HLA antigens in recurrent oral ulcerations. Arch Dermatol 1977; 113: 1717-9.

6 Gallina G, Cumbo V, Messina P, Caruso C. HLA-A, B, C, $D R, M T$ and $M B$ antigens in recurrent aphthous stomatitis. DR, MT and MB antigens in recurrent aphthous stom

7 Chajek-Shaul T, Pisanty S, Knobler H, et al. HLA-B51 may serve as an immunogenetic marker for a subgroup of patients with Behçet's syndrome. Am $\mathcal{J}$ Med 1987; 83: 666-72.

8 Gazit E, Brautbar C, Mizrachi Y, Cohen R, Yehoshua H, Zamir R. HLA polymorphism in Israel. 7. The Babylonian Jews. Tissue Antigens 1978; 11: 226-9.

9 Amar A, Zohar M, Tiwari J, Brautbar C. HLA and schizophrenia in Israel. Isr $\mathcal{f}$ Med Sci 1988; 24: 28-31. 